'llu. Revista de Ciencias de las Religiones

ISSN: $1135-4712$

https://dx.doi.org/10.5209/ilur.75202

\title{
El nacimiento de Dioniso en las Bacantes de Eurípides: la opinión de Cadmo y la de Tiresias
}

\author{
Sara Macías Otero
}

Recibido: 18 de julio de 2018 / Aceptado: 31 de diciembre de 2018

Resumen. Eurípides hace de la divinidad de Dioniso y su reconocimiento el tema central de Bacantes. Uno de los puntos fundamentales en el mito que determinan que Dioniso es un dios es la cuestión de su nacimiento; así, el trágico hace que distintos personajes lo mencionen desde diferentes puntos de vista. Nos presenta dos versiones claramente enfrentadas: por un lado Dioniso y sus fieles defienden que él es un dios hijo de Zeus y que por ello debe rendírsele culto. Por otro lado, Penteo, partiendo de la que fue la opinión de sus tías, considera que su tía Sémele, madre de Dioniso, mintió cuando afirmó que había engendrado un hijo de Zeus para encubrir así un desliz amoroso con un simple mortal; por eso, para el rey, Dioniso es un mortal. Pero, además, hay dos personajes, Cadmo y Tiresias, cuya actitud respecto al tema no es tan clara y ha dado pie a interpretaciones contrarias por parte de los estudiosos. En este trabajo analizo los pasajes de Bacantes que tratan sobre el nacimiento de Dioniso, con especial interés en aquellos en los Eurípides recoge o alude la opinión que ese hecho mítico merece a Cadmo y Tiresias, pues mi principal objetivo es intentar aclarar en medida de lo posible cuál puede ser la postura que el trágico hizo adoptar a esos dos personajes respecto a la divinidad de Dioniso.

Palabras clave: Bacantes de Eurípides; Cadmo; Tiresias; nacimiento de Dioniso.

\section{[en] The birth of Dionysus in Euripides' Bacchae: Cadmo's and Tiresias' opinions}

Summary. The main theme of Euripides' Bacchae is Dionysus' divinity and its recognition by the Thebans. The birth of Dionysus is a key point in the myth to determine that he is a god, consequently the playwright makes several of his characters mention it from different points of view. There are two versions clearly in conflict: on the one hand, Dionysus and his worshippers defend that he is a son of Zeus and, therefore, a god who must be venerated. On the other hand, Pentheus, assuming his aunts' view, thinks that his aunt Semele, who is Dionysus' mother, lied when she stated that she had conceived a son of Zeus, in order to conceal a love affair with a mere mortal. Therefore, in the king's opinion Dionysus is not a god but a mere human being. In addition, there are two characters, Cadmus and Tiresias, whose attitudes with regard to this matter are not so clear and have led scholars to interpret them in opposite ways. In this paper I am analyzing the passages of Bacchae on Dionysus' birth, with special emphasis on those where Euripides shows or refers to Cadmus' and Tiresias' opinions, since my aim is to try to clarify, as far as possible, which stand the playwright made those two characters adopt regarding to Dionysus' divinity.

Keywords: Euripides' Bacchae; Cadmus; Tiresias; Dionysus' birth.

1 Centro de Ciencias Humanas y Sociales, Consejo Superior de Investigaciones Científicas (CSIC).

Correo electrónico: saramaci@hotmail.com

ORCID iD: https://orcid.org/0000-0002-0837-5785 
Sumario. 1. Introducción. 2. Nacimiento de Dioniso: dos posturas enfrentadas. 2.1. Según el propio dios y sus fieles. 2.2. Según Penteo y las hermanas de Ágave. 3. Cadmo: habilidad política y diplomacia. 4. Tiresias: la explicación sofística de un adivino. 5. Conclusiones. 6. Bibliografía.

Cómo citar: Macías Otero, S. (2021), El nacimiento de Dioniso en las Bacantes de Eurípides: la opinión de Cadmo y la de Tiresias, en 'Ilu. Revista de Ciencias de las Religiones 24, 59-74.

\section{Introducción}

En Bacantes, Dioniso, disfrazado de extranjero, se presenta en Tebas con el objetivo de demostrar que es un dios y establecer su culto. La confrontación entre Dioniso y Penteo, que es el eje principal en torno al que gira la trama, representa el choque frontal entre la defensa de la divinidad de Dioniso y el rechazo de la misma. El rey cree en todo momento que aquel no es un dios y que sus cultos son una farsa, una mera excusa para encubrir comportamientos inadecuados ${ }^{2}$. El extranjero-Dioniso, a lo largo de la tragedia, intenta hacer cambiar de parecer al rey tanto verbalmente como con manifestaciones que son vistas por el resto de personajes como indudables intervenciones divinas ${ }^{3}$. Sin embargo, Eurípides hace que Penteo no sea capaz de retractarse de su opinión contraria a la divinidad de Dioniso, sino que, con cada uno de los intentos del extranjero-Dioniso por demostrarle que es un dios y que se le debe rendir culto, el rey se obceca más en su negativa. Ante ello el dios acaba por tomar medidas drásticas y lleva a efecto su venganza contra quienes se oponen a su culto ${ }^{4}$, siendo su punto culminante la muerte de Penteo que el trágico recrea con gran patetismo.

2 Penteo muestra constantemente una preocupación por el hecho de que los cultos en honor de Dioniso encubran comportamientos sexuales inadecuados entre las fieles y el extranjero-Dioniso, animadas por el consumo de alcohol $c f$. vv. 221-225, 236-238, 260-262, 353-354, 487, 814 y 957-958. En los vv. 778-779 el rey califica la actitud de las bacantes como un «insulto para los griegos».

3 A lo largo de la obra, Eurípides hace que las palabras con las que Dioniso intenta convencer a Penteo de que debe rendirle culto vayan acompañadas de actos extraordinarios, que para el resto de personajes son claras intervenciones divinas. Sin embargo, Penteo se niega a verlas como tales. Es, por ejemplo, el caso de cómo unas bacantes, que el rey había encarcelado, escapan al abrirse por sí solos los cerrojos y las cadenas que las retienen (vv. 443 y siguientes), o el de la fuerza sobrehumana que muestran las fieles cuando se enfrentan a los pastores que quieren apresarlas (vv. 728 y siguientes), o la escena en que Dioniso hace que el palacio tiemble como por un terremoto y afecta la mente de Penteo para que crea que también está teniendo lugar un incendio, además de que confunda al extranjero-Dioniso con un toro o una brillante luz (v. 622 y siguientes). La narración de la mayoría de estos prodigios la pone el trágico en boca de mensajeros, que se muestran impresionados ante lo que para ellos son signos de poder divino e, incluso, llegan a sugerir al rey que, ante estas pruebas, acepte a Dioniso como un dios (p.ej. vv. 769 y siguientes). Aunque todos estos temas están interrelacionados, en este artículo me centro exclusivamente en el nacimiento de Dioniso como punto fundamental que determina la opinión preconcebida de los distintos personajes sobre si aquel es un dios o no. Para un estudio pormenorizado de la figura de Dioniso en Bacantes, de sus prodigios y de la relación entre este y Penteo cf. Macías Otero 2020, 130-388.

$4 \quad$ El trágico deja claro en el prólogo que la intención de su Dioniso es hacer cambiar de opinión a aquellos que consideran que no es un dios e instaurar su culto, pero si estos pretenden usar la fuerza contra él o sus fieles, entonces el propio dios responderá también con violencia. Sin embargo, Dioniso no llega a Tebas con un plan de venganza preconcebido contra Penteo, como sucede por ejemplo en Hipólito donde Afrodita, al abrir la tragedia, narra cómo va a castigar a Hipólito y no se plantea darle ninguna oportunidad de retractarse ni intenta hacerlo razonar. Por el contrario, el Dioniso de Bacantes llega incluso a decir a Penteo que aún está a tiempo para evitar su desgracia, si cede y lo reconoce como dios (v. 802). Sin embargo, Eurípides marca un importante cambio en la actitud de Dioniso en los vv. 849-856, hecho que indica el paso a la segunda parte de la tragedia: cuando ya la paciencia del dios se agota porque Penteo no va a cambiar de parecer, aquel traza un terrible plan de venganza del que el rey no tendrá escapatoria. 
Eurípides establece desde el prólogo, por boca de Dioniso ${ }^{5}$ que la raíz de la negativa de Penteo a aceptarlo como un dios está en el hecho de que no cree que sea hijo de Zeus, sino de un mortal, y que para el rey todo el extraordinario mito del segundo nacimiento del dios del muslo de la divinidad suprema no es más que una patraña inventada por Sémele para ocultar un vergonzoso desliz. Por ello me parece importante centrarme en este trabajo en la opinión que Eurípides hace que nacimiento de Dioniso merezca a cada uno de sus personajes, pues es un elemento determinante a la hora de aceptarlo como dios. Y, sobre todo, me centraré en ciertos personajes secundarios, Cadmo, abuelo materno tanto de Penteo como de Dioniso ${ }^{6}$, y Tiresias, el adivino y consejero, cuyos pareceres respecto al nacimiento de Dioniso, y por tanto al hecho de si es realmente o no un dios, no son presentados por el trágico tan claramente como los de Penteo o los de las fieles del coro.

\section{Nacimiento de Dioniso: dos posturas enfrentadas}

\subsection{Según el propio dios y sus fieles}

Eurípides pone el prólogo en boca de Dioniso, quien explica que ha llegado a Tebas con el objetivo reivindicarse como dios hijo de Zeus, establecer su culto y acallar a quienes ponen en duda su divinidad ${ }^{7}$. Debido a esto el trágico hace que el propio Dioniso, ya al inicio de la tragedia, se presente como hijo del dios supremo y narre de manera resumida su primer nacimiento:

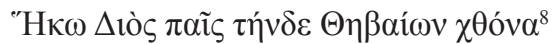

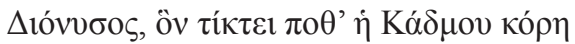

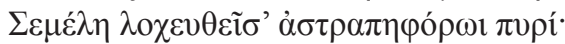
(...)

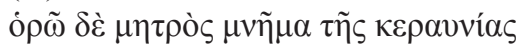

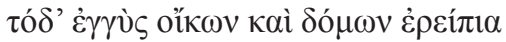

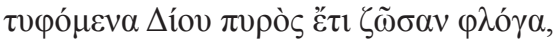

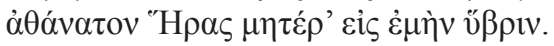

Llego a esta tierra de los tebanos yo, el hijo de Zeus, Dioniso, a quien una vez dio a luz la hija de Cadmo, Sémele, que se puso de parto por obra del fuego que acompaña al relámpago (...) Veo la tumba de mi madre, la fulminada por el rayo, aquí cerca de su casa, y las ruinas de su habitación humeantes por la llama del fuego de Zeus aún viva, inmortal injuria de Hera contra mi madre (vv. 1-9).

5 Bacantes es un gran juego de apariencias y realidad a varios niveles, que afecta sobre todo a la visión de Penteo. Así, en el prólogo, Eurípides ya hace que su Dioniso disfrazado de humano tome como «cómplice» al público, único conocedor de su verdadera identidad, mientras los personajes la ignoran.

6 Las madres de Penteo y de Dioniso, Ágave y Sémele respectivamente, son hermanas entre sí e hijas de Cadmo, Sémele tuvo a su hijo Dioniso con Zeus y Ágave a Penteo con Equión, uno de los supervivientes entre los nacidos de los dientes del dragón que Cadmo sembró.

7 Por ello encontramos en Bacantes frecuentes expresiones que hacen referencia a Dioniso como hijo de Zeus, $c f$. p.ej. vv. 1, 366, 417, 467, 551, 581, 603, 725, 860 y 1342. Para un estudio más detallado sobre estas expresiones cf. Macías Otero 2020, 169-175.

8 Para todos los pasajes citados sigo la edición de Diggle 1994, excepto cuando señalo lo contrario. La traducción es mía. En el v. 1 ofrezco la lectura de los manuscritos en vez de la de Diggle. 
En estos primeros 9 versos Eurípides incluye el nombre de Zeus dos veces: la intención sería que el propio Dioniso, desde el principio, reafirme ante el público su ascendencia divina, puesta en duda por el personaje de Penteo. Además, siguiendo la versión más extendida del mito, el trágico hace que el dios acuse a Hera como incitadora de la fulminación de Sémele y, por tanto, causante del nacimiento prematuro del $\operatorname{dios}^{9}$. Aunque de manera muy sintética y sutil ${ }^{10}$, Eurípides ha considerado necesario que Dioniso recuerde al público que Hera es la causante de la muerte de Sémele porque este es uno de los puntos fundamentales en los que difiere la opinión de los personajes que se enfrentan a Dioniso: la casa real tebana, como veremos, defiende que la muerte de Sémele es un castigo de Zeus.

Por otra parte, los extraordinarios acontecimientos que tienen lugar tras la muerte de Sémele y el nacimiento prematuro de Dioniso los presenta Eurípides por boca del coro en la párodos:

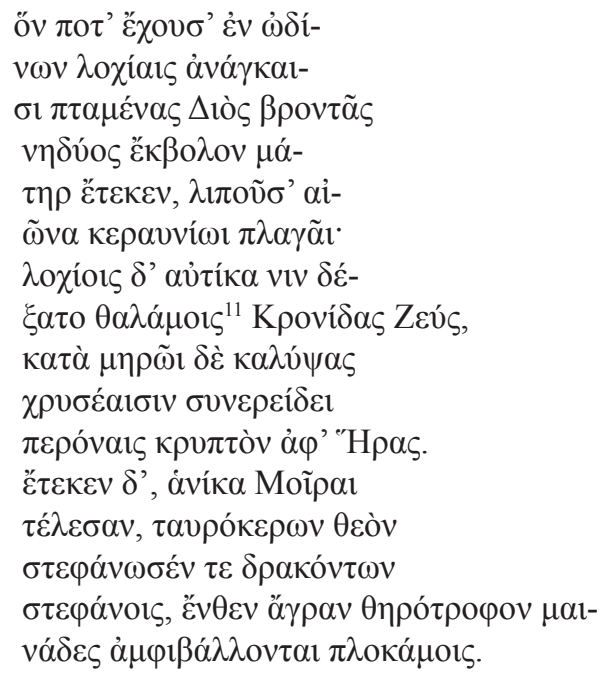

Al cual antaño, cuando el trueno de Zeus alzó el vuelo, su madre que lo llevaba en el seno, entre dolores por los esfuerzos del parto, lo dio a luz antes de tiempo, mientras abandonaba la vida por el golpe del rayo. En ese momento, en la habitación del parto lo recogió el Crónida Zeus, y cubriéndolo bajo la piel de su muslo lo sujetó con dorados broches, oculto de Hera.

9 La acción de Hera es calificada como hybris (v. 9) contra Sémele; lo normal es que sean los humanos quienes la cometen contra los dioses y no al contrario. Por boca de Dioniso, Eurípides parece juzgar moralmente la acción de Hera como si quien la hubiera cometido fuera una mortal. Censurar así a una diosa supondría una grave falta de respeto si quien lo hiciera fuera un hombre, sin embargo el trágico ha puesto esas palabras en boca de otro dios, por lo que no pueden ser reprobadas. Cf. Winnington-Ingram 1948, 18-19; Segal 1982, 81-86; Blaise 2003, 13-15. Para otras menciones del nacimiento de Dioniso en el corpus euripideo fuera de Bacantes, aunque mucho más breves, cf. Hipp. 449-454 y Ph. 649-650.

10 Eurípides no se habría extendido en los celos de Hera y cómo esta, por venganza, engaña a Sémele para causar su muerte a manos de Zeus, porque, al ser un mito ampliamente conocido, el público de la época entendería a la perfección esta breve alusión.

11 Conservo la lectura de los manuscritos, como también hacen Roux 1970 y Seaford 1996. Diggle 1994 prefiere

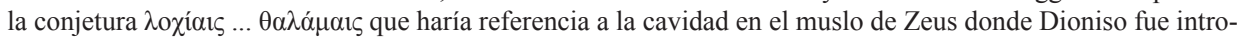
ducido, en lugar de a la habitación donde Sémele lo dio a luz y de donde lo habría recogido Zeus. 
Y él dio a luz, cuando las Moiras cumplieron su ciclo, al dios de cuernos de toro y lo ciñó con coronas de serpientes, de ahí que las ménades entrelacen en sus bucles esta presa depredadora de otras bestias (vv. 88-103).

Es una narración mucho más completa y detallada: incluye el segundo nacimiento, el que hace de Dioniso un dios tan especial, pues Zeus no es solo su padre, sino también, en cierta manera, su madre al darlo a luz él mismo de su muslo, donde terminó de formarse como si de un útero se tratara ${ }^{12}$. El trágico hace que, desde la perspectiva del coro, la vinculación entre Dioniso y Zeus sea mucho más profunda que la de otros dioses cuya divinidad no se pone en duda $^{13}$. Además, el coro, un poco más adelante, narra también cómo el propio Zeus revela a Dioniso ante Tebas como un dios nada más nacer este de Sémele, y le da los nombres rituales de Ditirambo y Baquio (vv. 519-529). La función dramática con la que Eurípides ha incluido estas detalladas narraciones de los nacimientos de Dioniso, en las que Zeus es sin duda su padre, es exponer claramente las creencias de los fieles, representados por el coro: Dioniso es un dios desde su nacimiento pues Zeus no solo lo concibió, sino que incluso lo dio a luz y lo legitimó como tal, precisamente ante Tebas. Nadie en la ciudad debería dudar de la divinidad de Dioniso y se le debería dar culto sin objeciones. Estas narraciones son la respuesta ante la negativa de Penteo y, por tanto de la ciudad de Tebas puesto que él es su representante, a aceptarlo como un dios de pleno derecho. El rey, desde la perspectiva de los fieles, está contraviniendo los designios de Zeus y, por tanto, cometiendo un «sacrilegio» que merece un castigo.

\subsection{Según Penteo y las hermanas de Ágave}

A la versión del nacimiento de Dioniso que cuentan el coro y el propio dios y que lo hace indudablemente hijo de Zeus, Eurípides opone la de Penteo que, a su vez, representa la opinión de su familia ${ }^{14}$ :

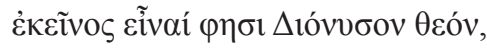

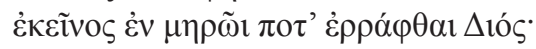

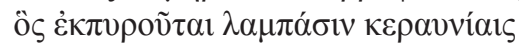

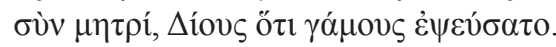

Aquel afirma que Dioniso es un dios, que estuvo antaño cosido al muslo de Zeus; el que fue fulminado por la luz de los rayos junto con su madre porque esta se inventó una unión con Zeus (vv. 242-245).

El trágico hace que para Penteo lo más difícil de creer de la historia que los fieles narran sobre el nacimiento de Dioniso sea que este es un dios y que Zeus lo tuvo

12 En los vv. 526-527 el hueco en el muslo de Zeus donde Baco va a terminar de gestarse es llamado «varonil útero».

13 Solo podría haber un caso comparable hasta cierto punto, el de Atenea que nace directamente de la cabeza de Zeus, $c f$. p.ej. Hes. Th. 886-900 y 924, Pi. O. 7.35-39, Apollod. 1.3.6, también Eurípides en Io $455-457$ hace una referencia al nacimiento de Atenea de la cabeza de Zeus.

14 Ya en los vv. 43-48 del prólogo a través de las palabras de Dioniso conocemos la postura de Penteo respecto a la ascendencia divina del dios. Y es en estos vv. 243-247 donde el trágico hace que el propio rey ratifique esas dudas sobre la paternidad de Zeus. 
cosido a su muslo. Sin embargo, el rey no pone en duda que Sémele, estando embarazada, muriera por el rayo de Zeus, aunque altera significativamente la interpretación de ese acontecimiento: para este personaje la fulminación de Sémele es un castigo del soberano de los dioses por afirmar esta que el hijo que esperaba era de él, cuando en realidad sería de un simple humano. Eurípides pone en boca de Penteo una interpretación de los hechos que no solo ofende a Dioniso, al dudar de su carácter divino, y a Zeus, al no creer que él mismo lo dio a luz por segunda vez y lo reveló como dios ante la ciudad, sino también a su propia tía Sémele que, según él, habría cometido un desliz sexual y lo habría intentado ocultar con un embuste. Con esta lectura del mito está, en cierta manera, menospreciando su propia estirpe, y, por ello, poco después el trágico hace que $\mathrm{Cadmo}^{15}$ le recomiende que, en lugar de tomar esa actitud contraria a la posible divinidad de Dioniso, la aproveche para traer prestigio a la casa real tebana al reconocer que un dios forma parte de la familia (vv. 333-336).

Pero Eurípides justifica en cierta manera esta interpretación aberrante que hace Penteo como una opinión que originariamente no habría sido de este personaje, sino una idea inculcada por su madre y sus tías. Así se puede deducir de las palabras de Dioniso:

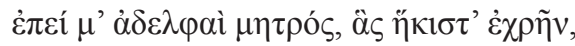

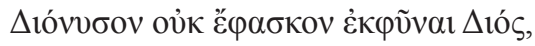

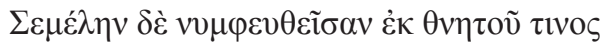

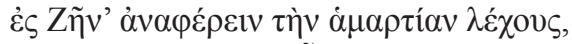

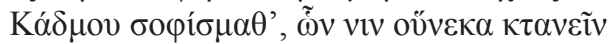

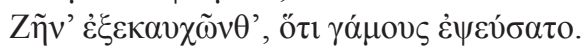

Debido a que las hermanas de mi madre, las que menos debieron hacerlo, decían que yo, Dioniso, no nací de Zeus, sino que Sémele, tras unirse con algún mortal, atribuyó a Zeus el desliz de su lecho, invenciones de Cadmo, a causa de las cuales proclamaban que Zeus la mató, porque fingió su unión con él (vv. 26-31).

Eurípides hace que Penteo (v. 245) use las mismas palabras que Dioniso mencio-

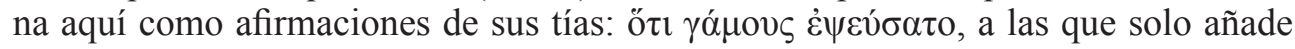
delante la especificación $\Delta$ íovs. Al repetir esas palabras, el trágico parece sugerir al espectador que el rey habría tomado su opinión sobre Dioniso de su propia familia. Esto tiene bastante sentido a la hora de construir la trama porque probablemente Eurípides habría situado el nacimiento de Dioniso en un momento en que Penteo aún no habría nacido o sería demasiado pequeño como para haberse formado una opinión propia sobre ello.

La versión que defiende Penteo del nacimiento de Dioniso como producto de un desliz que Sémele ha querido embellecer atribuyendo falsamente la paternidad a Zeus cumple en la tragedia la función de presentar la perspectiva de quienes dudan del mito y, desde el punto de vista religioso, pecan de impiedad y soberbia.

Eurípides, al recoger tan detalladamente ambas opiniones opuestas sobre el nacimiento del dios, y en consecuencia de su estatus divino, establece de manera muy clara el origen del enfrentamiento que es la base de la trama de la tragedia.

15 Eurípides traza a Cadmo como un personaje para el que, como veremos en el próximo apartado, el buen nombre de la familia es fundamental. 


\section{Cadmo: habilidad política y diplomacia}

Como acabamos de ver a través de las palabras de Dioniso en el prólogo, la postura de las hermanas de Sémele ante el embarazo y la muerte de esta era claramente malintencionada, pero ¿cuál es la opinión de la que Eurípides dota a Cadmo, el patriarca de la familia en ese momento? Volvamos a analizar más detenidamente ese pasaje del prólogo en el que también se menciona a Cadmo (vv. 26-31): a primera vista resulta un pasaje bastante sencillo, pero que en realidad presenta una serie de complicaciones a la hora de deducir la postura de Cadmo respecto al nacimiento de

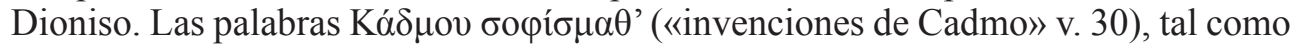
están colocadas en la frase, quedan lo suficientemente ambiguas como para dar pie a distintas interpretaciones. En la mayoría de los comentarios ${ }^{16}$ se explican como una aposición a la oración de infinitivo inmediatamente anterior $\Sigma \varepsilon \mu \varepsilon \dot{\lambda} \eta \eta v(. ..) \dot{\varepsilon} \varsigma$ Z $\tilde{\eta} v$ '

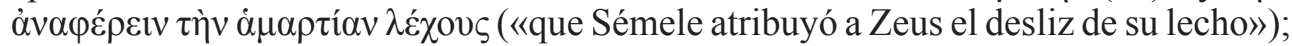
interpretan así que las hermanas de Sémele afirman que Cadmo habría inventado, como excusa para el indecente comportamiento de aquella, la historia de que fue precisamente Zeus quien la dejó embarazada. Ellas consideran que la muerte de Sémele se debe a la indignación del padre de los dioses por su calumnia. Por lo tanto, Cadmo habría defendido desde el principio que Dioniso es hijo de Zeus, ya lo creyera realmente o no, con el fin de evitar el escándalo. Pero en opinión del resto de sus hijas la historia es una falsedad, una argucia de Cadmo para cubrir la desvergüenza de Sémele. Eurípides habría hecho que Dioniso con las palabras Kó $\delta \mu o v ~ \sigma o \varphi i ́ \sigma \mu \alpha \theta$ ' reflejara el punto de vista de las hermanas, no el suyo propio.

Pero además, en mi opinión, es posible otra interpretación de la aposición ${ }^{17}$ : Kód$\delta \mu$ ov бофí́ $\mu \alpha \theta^{\prime}$ 'sería aposición a todas las oraciones de infinitivo que sirven de complemento a é $\varphi \alpha \sigma \kappa o v$; así, debería entenderse que Cadmo ha inventado la historia que cuentan las hermanas de Ágave: que Sémele tuvo relaciones con un mortal pero fingió unirse a Zeus para disimular su desliz. Se trata aquí del punto de vista del propio Dioniso.

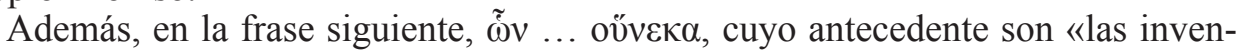
ciones de Cadmo», puede interpretarse como complemento del verbo principal $\grave{\varepsilon} \xi \varepsilon-$ $\kappa \alpha v \chi \tilde{\omega} \vee \theta$ ' y no del infinitivo $\kappa \tau \alpha v \varepsilon i ̃ v$; es decir las hermanas de Sémele habrían tomado como punto de partida las afirmaciones de Cadmo de que su hija en realidad estaba embarazada de un mortal pero se lo atribuía a Zeus, y las habrían hecho públicas ${ }^{18}$ yendo un paso más allá en su infamia al afirmar que la muerte de aquella fue un castigo del dios supremo por sus mentiras. Ellas habrían sido las encargadas de difundir y aumentar un falso rumor que habría tenido su germen en alguna opinión vertida por Cadmo en privado.

16 Cf. p.ej. los comentarios de Dodds 1944; Roux 1972; González Merino 2003; la traducción de Kovacs 2002 y el estudio de Mirto 2010, 18.

17 Esta interpretación ha sido propuesta y defendida por estudiosos como Wilamowitz en su traducción (tal como señala Dodds 1944, ad loc.); Deichgräber 1935, 327; Kitto 1939, 375; Garvie 2016, 110.

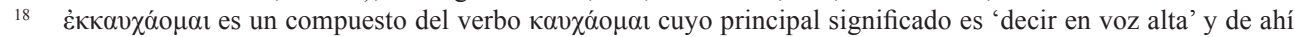
también 'jactarse', traducción que se le suele dar en este pasaje euripideo. Sin embargo, siguiendo a Dodds 1944 y a Tovar 1960, me parece que debería traducirse como 'pregonar', 'hacer público' pues el preverbio $\grave{\varepsilon} \xi$ - añadiría el matiz de 'hacia fuera'. Es decir, que lo que se comentaba en el seno de la familia, ellas lo habrían hecho público. El verbo parece también tener cierto matiz peyorativo que dejaría entrever la opinión del propio Dioniso. 
Ambas interpretaciones de la aposición son viables, pero en mi opinión quizá la segunda sería algo más apropiada pues no resultaría extraño que el trágico hubiera hecho que Dioniso ofreciera su perspectiva al exclamar «invenciones de Cadmo» con carácter parentético, dado que, un poco antes, al inicio de la explicación de lo que las hermanas de Sémele decían respecto a su embarazo, se incluye también una oración parentética en la que claramente Dioniso expresa su propia opinión: «las que menos debieron hacerlo» (v. 26). Lo fundamental para interpretar la postura de Cadmo es la perspectiva desde la que se entiende que habla Dioniso al mencionar las «invenciones de Cadmo»: si se considera que es el punto de vista de las hermanas el que ofrece, las mentiras de Cadmo harían referencia al hecho de que Dioniso es hijo de un dios. La versión de Cadmo sería contraria a la de las hermanas de Sémele. Pero, si se considera que Dioniso ofrece su propio punto de vista, las invenciones de Cadmo serían las calumnias que lo hacen hijo de un mortal. En este caso Cadmo se habría opuesto a creer que Dioniso es un dios y, posteriormente, habría cambiado de opinión con la llegada del extranjero y de los cultos dionisíacos. Su motivación para ese cambio de opinión habría sido, sobre todo, política y de conveniencia.

Para apoyar la primera interpretación de la aposición según la cual Dioniso implicaría que Cadmo creyó en su divinidad desde su nacimiento, los estudiosos ${ }^{19}$ señalan tres pasajes:

- Los versos 10-11 donde Dioniso alaba a Cadmo por convertir en un santuario el lugar donde Sémele murió. En mi opinión estos versos no dan una base demasiado firme para considerar a Cadmo un fiel creyente en Dioniso: a lo largo de la obra Eurípides muestra que la mayor preocupación del viejo rey es mantener el honor y la buena imagen de la familia ${ }^{20}$, por lo que no sería descabellado que este hubiera rendido las mayores honras funerarias a su hija, como corresponde a un miembro de la casa real, a pesar de que no creyera la historia de su unión con Zeus. Además, con ello, habría aprovechado para intentar acallar las críticas públicas en contra del honor de Sémele. Vemos que su actitud es la misma hacia Penteo: a pesar de que este comete tremendos actos de hybris, Cadmo ordena que su cuerpo desmembrado sea recogido para poder sepultarlo como corresponde (vv. 1216 ss.).

- Los versos 180-183 donde Cadmo, vestido con los atavíos dionisiacos, dice que es necesario honrar a Dioniso. Considero que esto tampoco es una prueba irrefutable de que Eurípides ideara a Cadmo como un personaje que creyó en la divinidad de Dioniso desde su concepción: el viejo rey podría estar dándole ahora el beneficio de la duda, puesto que su culto se está extendiendo y haciendo fuerte. El trágico podría haber dotado a su personaje de una actitud práctica, y un tanto oportunista, desde el punto de vista político y social: Cadmo podría considerar que si acepta a Dioniso como un dios, lo sea o no, los beneficios para su familia serían evidentes al estar emparentados con él. Por otro lado, si lo rechazan, y finalmente resulta ser cierto que es hijo de Zeus, las consecuencias serían terribles. Aceptando la divinidad de Dioniso (lo que no implica que realmente crea en ella) se asegura de que ningún posible perjuicio les sobrevenga y de que, en todo caso, obtengan fama y beneficios por ello. Lo que

Dodds 1944, 67; Seaford 1996, 152.

$20 \quad C f$. p.ej. Leinieks 1996, 328s. y los vv. 333-342 de los que hablo inmediatamente a continuación. 
realmente le importaría a Cadmo es que Dioniso pertenece a su linaje y no que realmente sea un dios; así, la primera vez que Cadmo habla de Dioniso en escena (v. 181) lo llama «hijo de mi hija» y no «hijo de Zeus», haciendo hincapié en que se trata de un miembro de su familia, no en que es un hijo del dios supremo $^{21}$.

- Los versos 333-336 donde Cadmo, al ver a Penteo completamente obcecado contra el culto a Dioniso, intenta convencerle de que si no puede aceptarlo como un dios, lo más conveniente es que finja que cree que lo es:

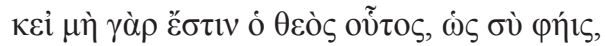

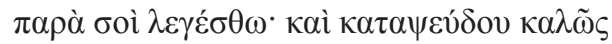

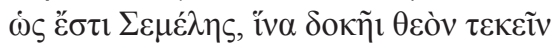

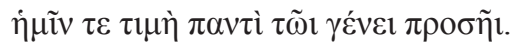

Aunque este no fuera un dios, como tú afirmas, en lo que a ti respecta, que se diga que sí. Incluso finge de manera apropiada que es hijo de Sémele para que parezca que dio a luz a un dios y se nos endose este honor a todo nuestro linaje.

La expresión «aunque este no sea un dios» parece que deja abierta la posibilidad de que realmente no lo sea. La recomendación a Penteo por parte de Cadmo de fingir que cree que Sémele dio a luz un dios, además del hecho de que no menciona a Zeus como padre, parece dejar entrever que Eurípides ha concebido a Cadmo como un personaje que en el fondo tampoco cree que de verdad el soberano de los dioses sea el padre de Dioniso, pero que finge creerlo por conveniencia. Estaría aconsejando a Penteo tomar la misma actitud diplomática que él ha tomado. Así, estos versos no me parecen un argumento de peso para apoyar la creencia de Cadmo en la divinidad de Dioniso, sino que más bien podrían utilizarse para argumentar lo contrario ${ }^{22}$.

Con este propósito podemos traer a colación también el momento en que Cadmo entra en escena, junto con Tiresias, ataviado como un baco para intentar convencer a Penteo de que se una al culto, lo que provoca la sorpresa y risa de este (vv. $248 \mathrm{ss})^{23}$. Se trata de una risa amarga porque considera totalmente grotesca la actitud de estos dos hombres debido a su edad demasiado avanzada para participar en esa clase de ritos $^{24}$. Pero el disgusto y la indignación que Eurípides hace que Penteo muestre son

${ }^{21}$ En el v. 278, Tiresias llama a Dioniso «hijo de Sémele», lo que puede dar lugar a interpretaciones opuestas respecto a la creencia o no del adivino en que Dioniso sea hijo de Zeus: como está intentando convencer a Penteo de que no se oponga al nuevo culto, esta forma de referirse al dios podría ser una manera sutil de recordarle que es un miembro de su familia y que si acepta su divinidad, incluso, sería beneficioso para su posición social y política, como también Cadmo parece opinar. Sin embargo también se puede interpretar de la manera contraria considerando que es una especie de desliz de Tiresias llamar así a Dioniso y no «hijo de Zeus» porque en el fondo no creyera en su condición divina.

22 Apoyan esta visión de Cadmo como un fingido fiel por conveniencia Winnington-Ingram 1948, 54; Verdenius 1988, 264; Rijksbaron 1991, 55; Seidensticker 2016, 278 n. 19 y 282 n. 44; Susanetti 2016, 290, pero consideran que esta actitud de Cadmo podría haberse dado ya desde el nacimiento de Dioniso. En contra de la falta de sinceridad de Cadmo, cf. Roux 1972, 360; Leinieks 1996, 41-47; Seaford 1996, 179; Mirto 2010, 18 y 21.

23 Sobre el posible carácter cómico de este episodio que desentonaría con la seriedad y patetismo del resto de la tragedia, $c f$. Norwood 1908, 23; Deichgräber 1935; Kitto 1939, 379; Winnington-Ingram 1948, 40-44; Dodds 1944, 86; Seidensticker 1978 y 1982, 115-129. En contra Murray 1921, 56-87; Rivier 1975, 88-89; Ugolini 1995, 202-204; Donzelli 2006. Sobre la risa en Bacantes cf. Macías Otero (en prensa).

24 Sin embargo Tiresias en los vv. 206 y siguientes ha señalado que cualquiera, independientemente de su edad, puede participar en los ritos de Dioniso. 
tan viscerales ${ }^{25}$ que podría entenderse que hay más factores que molestan al rey: en cuanto a Tiresias, no olvidemos que es el sacerdote de Apolo, supuestamente el dios opuesto a Dioniso, por lo que para Penteo sería muy sorprendente que precisamente el adivino rindiera culto a Dioniso; podría ser visto como un acto de hipocresía o traición. Sin embargo, Eurípides por boca del propio Tiresias justifica esa actitud al señalar que Apolo y Dioniso no son opuestos sino complementarios, pues incluso comparten culto en Delfos, y además añade que Dioniso está estrechamente relacionado con el arte de la adivinación, del que él es un profesional ${ }^{26}$.

Por otro lado, me resulta muy creíble que el trágico hubiera hecho sentir a Penteo una furia desmedida por ver a Cadmo participar en los ritos báquicos si ese personaje conociera que su abuelo no había creído hasta el momento en la divinidad de Dioniso; el cambio de opinión de Cadmo le habría resultado a Penteo cuanto menos indignante $\mathrm{y}$, por ello, intenta buscarle una explicación culpando a Tiresias de haberlo convencido de que honre a Dioniso (v. 255) ${ }^{27}$. No me parece inadecuado pensar que esas acusaciones de convencer y «corromper» a Cadmo para que participe en el culto báquico que Penteo vierte contra Tiresias impliquen la idea de que Cadmo se opusiera antes a esos cultos. Y esto me conduce a pensar que sería más apropiado interpretar las palabras de Dioniso en el prólogo sobre las «invenciones de Cadmo» de la segunda manera que hemos propuesto: como la opinión de Dioniso que afirma que Cadmo, que habría creído que la historia de Sémele era una pobre excusa para un desliz, dio origen a la idea de que no es hijo de Zeus, sino de un mortal; rumor que se habría hecho público gracias a la malevolencia e indiscreción de las hermanas de Sémele.

Por último, respecto a este tema de la opinión de Cadmo, hay que tener en cuenta la profecía que Eurípides pone en boca de Dioniso al final de la tragedia, cuando ya todos han reconocido que es un dios: Cadmo acabará sus días transformado en una monstruosa serpiente, junto a su esposa Harmonía que también se metamorfoseará, y dirigirá un ejército contra su propia patria. Cuando llegue el momento de su muerte irá a la isla de los Bienaventurados (vv. 1330-1339). Algunos estudiosos han considerado que este destino, la vida eterna ${ }^{28}$, es un premio que el dios otorga a Cadmo, lo que implicaría que este siempre ha defendido la divinidad de Dioniso ${ }^{29}$. Sin embargo la reacción de Cadmo a esa profecía parece indicar todo lo contrario: suplica piedad al dios y admite que han estado equivocados respecto a él (v. 1344). Para esto

25 Además de reiterar la vergüenza que siente por verlos participar en los ritos, llega a amenazar a Tiresias con la posibilidad de encarcelarlo junto a las bacantes, si no fuera porque el respeto a sus canas se lo impide (vv. 258260).

26 Cf. vv. 306-309 y 298-301 respectivamente.

27 En el v. 345, Penteo llama a Tiresias «maestro de la insensatez» de Cadmo.

28 Es muy probable que la vida eterna le venga otorgada a Cadmo por ser el esposo de una diosa, Harmonía, lo que en principio debía ser un premio, pero Eurípides ha hecho que Dioniso transforme ese acontecimiento en un castigo eterno: para Cadmo, que a lo largo de la obra se caracteriza por considerar su estirpe real como lo más importante, será insoportable el sufrimiento tanto por la muerte de su heredero Penteo y por la destrucción de toda su familia, como por saberse causante del enfrentamiento contra su patria y la destrucción del santuario de Apolo. Y se trata de un sufrimiento interminable, pues no puede ni siquiera contar con la muerte para acabar con él. Dioniso tendrá para él el resultado opuesto al que tiene para sus fieles: no liberará a Cadmo de sus pesares sino que lo encadenará a vivir con ellos por toda la eternidad. Esto justificaría las palabras de rechazo que el trágico pone en boca de Cadmo cuando oye la profecía.

29 Cf. Riu 1999, 92-105. 
último usa una primera persona del plural, es decir se incluye entre los errados ${ }^{30}$, y Dioniso en su respuesta le incluye también entre quienes lo han ofendido, pues usa una segunda persona del plural (vv. 1345 y 1347).

Todo esto podría servir como apoyo a la hipótesis de que Eurípides habría concebido a Cadmo como un personaje que realmente no creía en que Dioniso fuera hijo de Zeus y que su cambio de opinión se debe a precaución y conveniencia; Eurípides hace que la actitud de Penteo hacia Cadmo sea tan despectiva y violenta porque el rey está defendiendo la idea que desde muy pequeño su madre, tías y abuelo le habrían inculcado y no comprende cómo este último se desdice de lo que lleva años afirmando ni por qué intenta que él mismo cambie de idea.

El trágico habría conformado el personaje de Cadmo como el prototipo de gobernante diplomático que, al contrario que Penteo, puede cambiar o suavizar una opinión con el objetivo de beneficiar a la casa real y a la ciudad. Prefiere desdecirse de su opinión sobre el nacimiento y divinidad de Dioniso, aunque en el fondo pueda no estar convencido, con tal de evitar un posible daño. Es un hombre político y práctico que busca soluciones rápidas y convenientes sin entrar en discusiones teológicas.

\section{Tiresias: la explicación sofística de un adivino}

Por su parte Eurípides conforma el personaje de Tiresias como un apoyo para el de Cadmo, pues pretende también que Penteo cambie su actitud hacia Dioniso y, para ello, le da una explicación del nacimiento de este en la que intenta suavizar algunos de los detalles que podrían producir más incredulidad en el rey, como es el hecho de que terminara de gestarse en el muslo de Zeus:

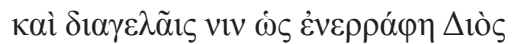

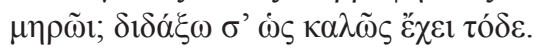

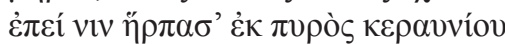

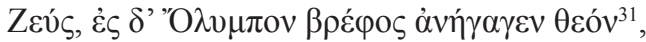

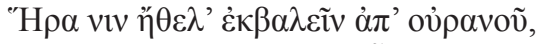

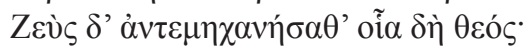

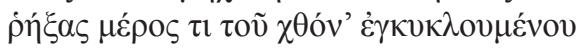

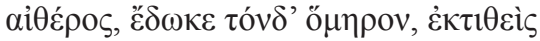

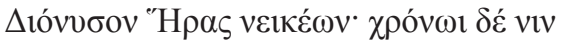

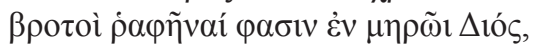

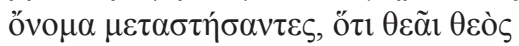

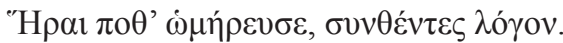

30 Sin embargo, es destacable que, antes de que Dioniso haga su epifanía y exponga la profecía, Cadmo se excluye de haber ofendido al dios y culpa a Ágave y sus hermanas (vv. 1297 y 1302- 1304, donde usa la segunda persona del plural). ¿Por qué habría cambiado su actitud cuando tiene al dios delante? ¿Quizá porque sabe que no puede fingir su inocencia ante él? ¿O porque aunque defendió a Dioniso, ante él se incluye en el pecado cometido por sus hijas por solidaridad familiar y para interceder por ellas?

31 Los manuscritos ofrecen esta lectura. Siguiendo a Dodds 1944 y Roux 1970, no considero necesario corregirla por véov, tal como acepta Diggle 1994 a partir de la edición aldina, pues aquí Eurípides estaría intensificando que Dioniso es un dios desde que nació, y como tal Zeus lo lleva al Olimpo. El hecho de que dos versos después aparezca $\theta \varepsilon o ́ s$, también a final de verso, podría ser una repetición intencionada del trágico para insistir en la divinidad de Dioniso desde su nacimiento, tema principal de la tragedia. 
¿Y te mofas de él porque fue cosido al muslo ( $\mu \eta \rho \tilde{\omega} \imath)$ de Zeus? Te enseñaré cómo eso es correcto: una vez que Zeus lo sustrajo del fuego del rayo, subió al Olimpo al recién nacido, un dios. Hera deseó arrojarlo lejos del cielo, pero Zeus maquinó en respuesta un plan digno de un dios: rasgando una parte ( $\mu \varepsilon ́ \rho \varsigma$ ) del éter que envuelve la tierra a la ojeriza de Hera se la entregó como prenda (ő $\mu \eta \rho o v)$, tras haber modelado con ella un Dioniso. Con el tiempo los mortales dijeron que este fue cosido al muslo ( $\mu \eta \rho \tilde{\omega} \mathrm{i})$ de Zeus, cambiando el nombre, porque el dios una vez fue rehén $(\dot{\omega} \mu$ $\rho \varepsilon v \sigma \varepsilon)$ de la diosa Hera, así conformaron el mito (vv. 286-297) $)^{32}$.

Eurípides incluye aquí una explicación de estilo sofístico en la que abundan los juegos de palabras y falsas etimologías basadas en semejanzas fonéticas ${ }^{33}$. Tiresias intenta racionalizar el nacimiento de Dioniso diciendo que, con el transcurrir del tiempo, se ha producido una confusión fonético-lingüística entre las palabras $\mu \varepsilon ́ p o \varsigma$

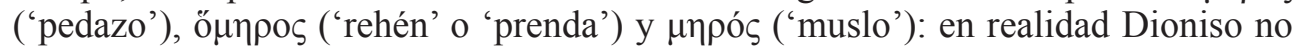
habría sido introducido en el muslo de Zeus, sino que este, al percibir la animadversión de Hera hacia su hijo, habría creado a partir de un pedazo de éter una imagen de Dioniso y se la habría entregado a Hera como rehén para aplacarla ${ }^{34}$. La historia del muslo habría sido un invento producto de la degeneración que habría ido sufriendo la supuesta «realidad» al irse transmitiendo entre los mortales ${ }^{35}$.

Tiresias podría representar con este discurso la tendencia a racionalizar mitos y leyendas por parte de sofistas y logógrafos en época del trágico. Penteo, por su parte, encarnaría a aquellos que necesitan esa interpretación más racional para poder seguir creyendo. El discurso de Tiresias desde el punto de vista formal está compuesto de manera muy cuidada y, en cuanto al contenido, recoge ideas filosóficas propias de la época de Eurípides que parecen ser reflejo de las teorías de Empédocles y Pródico, además de añadir también elementos del pensamiento presocrático ${ }^{36}$.

32 Sobre la posibilidad de que el pasaje fuera espurio y su refutación, además de la hipótesis de la existencia de una laguna en él, $c f$. Dodds 1944, 106-108. En contra de la laguna Roux 1972, 349s.

33 Sobre el carácter sofístico de este discurso $c f$. Gallistl 1979; Roth 1984; Egli 2003, 136-146; Di Benedetto 2004 , 88-93; Mirto 2010, 11-21; Encinas Reguero 2011, 135-139; Seidensticker 2016, 278-283. Este tipo de explicaciones pseudoetimológicas son frecuentes en el Cratilo de Platón (p.ej. 396d y 404e-406c). Asimismo, Santamaría 2012, Ferrari 2013 y Piano 2016, 297-300 han estudiado los importantes paralelismos entre esta explicación que Eurípides presenta en boca de Tiresias y el comentario contenido en el Papiro der Derveni. Para el papel que desempeñan la etimología y los juegos fonéticos en el orfismo de una manera más general, $c f$. Casadesús 1997; Bernabé 2008.

34 La creación de una imagen o fantasma de éter para evitar cualquier tipo de agravio se da en bastantes ocasiones en la literatura griega: es famosa la palinodia de Estesícoro donde la honra de Helena queda intacta gracias a este recurso y el propio Eurípides en su Helena (vv. 17-21, 256- 259) se hace eco de ello. Pero también hay otros mitos donde una imagen ilusoria es usada de manera semejante: por ejemplo, Píndaro (P. 2.36-37) cuenta cómo Ixión, que pretendía unirse a Hera, fue engañado con una imagen de ella hecha a partir de una nube y Platón (Smp. 179bc) dice que a Orfeo, que creyó haber tenido éxito en el rescate de Eurídice, los dioses infernales le entregaron una imagen fantasmal de ella. Para más ejemplos, $c f$. Gentili 1995, ad Pi. P. 2.36.

35 Se produciría aquí un sutil anacronismo y rotura de la ilusión trágica: las palabras de Tiresias implican que la historia del nacimiento de Dioniso se ha ido distorsionando en su transmisión. Eurípides hace que el nacimiento del dios parezca un hecho muy lejano; sitúa a Tiresias por un momento en su propio tiempo, en el s. V a.C., en el que el nacimiento de Dioniso es un mito remoto; sin embargo, en el marco temporal de la trama de la tragedia desde este acontecimiento hasta que el dios ha vuelto a Tebas para instaurar su culto no habría pasado tanto tiempo como para que el mito se transforme.

36 Cf. Lloyd 1964; Henrichs 1975, 107-110 y n.64; Roth 1984, 59-61; Egli 2003, 143; Di Benedetto 2004,325 y 338-339; Edmonds 2013, 131-132. Además se ha considerado que el discurso podría tener implicaciones místicas más profundas en relación con ciertas especulaciones filosóficas en las que se da una equivalencia a los dioses con elementos cosmológicos como el éter, $c f$. Winnigton-Ingram 1948, 50; Seaford 1996, 174-176. 
Lo verdaderamente sugerente es que sea Tiresias, y no otro personaje, quien intente dar una visión más racional del nacimiento de Dioniso: Tiresias es el adivino y sacerdote al servicio de los dioses que debería representar las creencias tradicionales. Sin embargo, su intención en ese momento parece ser evitar una desgracia a Tebas y a la casa real intentando convencer a Penteo de que no se oponga al dios, y, si para ello debe poner, como último recurso, la lógica al servicio de las creencias religiosas para que Penteo pueda aceptarlas, lo hace sin miramientos.

Con todo esto parece que Tiresias no pone en duda la divinidad de Dioniso ${ }^{37}$, sino que combina sus conocimientos filosóficos con su fe, poniendo siempre los primeros al servicio de la religión; reflejaría un tipo de sacerdotes eruditos, ya comunes en época de Eurípides, entre los que podríamos contar como un ejemplo el comentarista del Papiro de Derveni ${ }^{38}$. Para apoyar esta idea de que Eurípides ha concebido a Tiresias como un creyente en la divinidad de Dioniso hay además algunos indicios en la tragedia que muestran al adivino como un defensor de las creencias tradicionales (vv. 200-203), e incluso podría haber en este mismo discurso un reconocimiento de Dioniso como dios, si se acepta la lectura $\theta \varepsilon$ cóv de los manuscritos en el v. $289^{39}$.

Sin embargo también cabe la posibilidad de interpretar la opinión de la que Eurípides dota a Tiresias de manera contraria ${ }^{40}$ : aunque el adivino parezca defender los valores tradicionales en los versos 200-203, bien podría dejar ver en su discurso posterior su verdadera postura; que en el fondo no cree tanto en ellos y que pone la lógica por encima de los mitos y la fe. A pesar de que su intención sería hacer más creíble el mito eliminando los detalles que podrían parecer más grotescos, el resultado final es una historia igual de inverosímil ${ }^{41}$, a lo que hay que añadir que ha utilizado recursos sofísticos e ideas de filósofos como Pródico, conocidos por sus feroces críticas a las creencias tradicionales, detalles que precisamente apuntan hacia la posibilidad de que Tiresias, en su fuero interno, tenga la actitud de quien comienza a poner en duda supuestas verdades que establecen las creencias tradicionales ${ }^{42}$.

Por mi parte considero que las dos hipótesis respecto a la actitud de Tiresias tienen argumentos que las sostienen, y que probablemente Eurípides haya optado por ser ambiguo en este caso. En la actitud del adivino podría encerrarse una crítica del trágico hacia los sofistas y logógrafos que abundaron en su época intentando explicar «racionalmente» las antiguas leyendas y creencias ${ }^{43}$, pero también podría haber un pequeño guiño hacia el escepticismo del propio trágico respecto a esas creencias tradicionales, que le resultarían ya insuficientes ante ciertas inquietudes existenciales ${ }^{44}$.

37 Conacher 1967, 62; Mirto 2010, 17; Santamaría 2012, 682s.

38 Sobre estos sacerdotes eruditos y los paralelos entre Tiresias y el comentarista de Derveni, cf. Santamaría 2012, 680-682.

39 Cf. n. 31.

40 Wilamowitz y Winnington-Ingram 1948, 56 n. 3 consideran que Tiresias no cree en verdad en el mito de nacimiento de Dioniso y que su actitud es hipócrita. Encinas Reguero 2011 también comparte esta opinión y la reafirma con una serie de detalles, sobre todo en relación a cómo el adivino nombra a Dioniso en determinados contextos y evita decir su nombre en otros. Sin embargo, Dodds 1944, 116 está en contra de la supuesta hipocresía del adivino.

41 Winnington-Ingram 1948, 50.

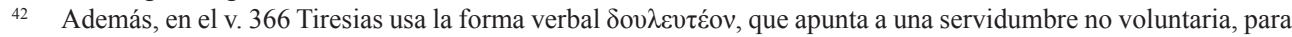
referirse al culto de Dioniso.

$43 \quad$ Al respecto, $c f$. Diller 1955, 462; Roux 1972, 348; Oranje 1984, 47-49.

44 En el corpus euripideo hay varios pasajes en los que Eurípides parece poner en boca de sus personajes su escepticismo sobre la mitología, p.ej. en Hel. 17-21 y 256-259, IA 71-72, Tr. 971-981. 


\section{Conclusiones}

En Bacantes Eurípides presenta el nudo de la trama, la defensa o negación de que Dioniso sea un dios, principalmente a través de dos versiones enfrentadas del nacimiento de Dioniso: para el propio dios y sus fieles no hay duda de que es hijo de Zeus y, a consecuencia de ello, su naturaleza es divina. El trágico incluso hace afirmar a los fieles que Dioniso terminó de gestarse en el muslo de Zeus y tuvo un segundo nacimiento, por lo que su vinculación con el dios supremo es más estrecha que la de la mayoría de los otros dioses hijos suyos, cuya divinidad no es puesta en entredicho. Por otro lado está la versión opuesta, la de la familia real tebana, cuyo defensor principal es el personaje de Penteo: desde su perspectiva Dioniso es un mortal, pues Sémele había quedado encinta de un simple humano y para ocultar su desvergüenza había atribuido la paternidad a Zeus. Este, indignado por esa calumnia, la fulminó como castigo.

Pero también hemos observado que Eurípides hace que de dos de sus personajes, Cadmo y Tiresias, tomen una postura difícil de desentrañar. No está claro si apoyan una u otra versión, $\mathrm{y}$, en el caso de que lo hagan, si es de manera sincera o únicamente por conveniencia. Tras analizar detalladamente la actitud de Cadmo y las palabras iniciales de Dioniso en el prólogo, donde resume el origen de las dudas vertidas sobre su condición divina, considero bastante probable que Eurípides haya modelado a Cadmo como el prototipo de diplomático y político: no es un verdadero creyente de Dioniso, sino que ha considerado más beneficioso y conveniente desde el punto de vista político y social someterse al nuevo culto y aceptar la divinidad de Dioniso.

Respecto a la opinión de Tiresias, que también ha sido interpretada de muy diferentes maneras por los estudiosos, considero muy aceptable la teoría de que el trágico estuviera reflejando a través de él la existencia en su época de un tipo de sacerdotes ilustrados, que recurrían a la filosofía para explicar determinadas cuestiones mitológicas que, de otra manera, habían comenzado ya a resultar increíbles o dudosas para algunas personas. El sacerdote no es un descreído, sino que pone al servicio de la religión sus conocimientos científicos para devolver o afianzar la fe de aquellos que empiezan a dudar. En la tragedia el máximo representante de estos últimos sería Penteo.

Eurípides, que a lo largo de toda su obra muestra en varias ocasiones una angustia ante cuestiones a las que la religión tradicional no daba solución, a través de las interacciones entre Penteo y Tiresias en Bacantes podría reflejar cómo en su época el sistema religioso se estaba adaptando a las nuevas formas de pensamiento más exigentes y analíticas.

En definitiva, el tema del nacimiento de Dioniso en Bacantes no es algo superficial, pues dependiendo de la concepción que se tenga sobre él se creerá que Dioniso es un dios o no y, por tanto, se le rendirá culto o no. Desde ambas posturas la contraria supone un sacrilegio: para los personajes que creen a Dioniso hijo de Zeus, negarlo es cometer hybris que debe ser castigada. Para aquellos que creen que Dioniso no es un hijo de Zeus la actitud sacrílega sería la de los que defienden lo contrario, pues están haciendo pasar por un dios a un simple humano. Sin embargo es muy difícil desentrañar la verdadera intención de Eurípides al componer la obra: podría haberla concebido como una defensa al dios y su culto o, por el contrario, como una crítica sutil, motivada por el hecho de que habría comenzado a dudar de la religión tradicional. 


\section{Bibliografía}

Bernabé, A., 2008, "Etimologías, juegos fónicos y gráficos en los textos órficos” en Bernabé, A.-Casadesús, F. (eds.), Orfeo y la tradición órfica: un reencuentro, Madrid, 867-896.

Blaise, F., 2003 , “L'experience delirante de la raison divine: les Bacchantes d'Euripide", Methodos 3. https://journals.openedition.org/methodos/239?file=1 (acceso: 1/11/18).

Casadesús, F., 1997, “Gorgias 493a-c: la explicación etimológica, un rasgo esencial de la doctrina órfica" en Actas del IX Congreso Español de Estudios Clásicos, vol. II, Madrid, 61-65.

Conacher, D. J., 1967, Euripidean Drama. Myth, Theme and Structure, Toronto.

Deichgräber, K., 1935, “Die Cadmos-Teiresiasszene in Euripides Backen”, Hermes 70, 322349.

Di Benedetto, V., 2004, Euripide. Le Baccanti, Milano.

Diggle, J., 1994: Euripides. Fabulae. III, Oxford.

Diller, H., 1955, "Die Bakchen und ihre Stellung im Spätwerk des Euripides”, Akademie der Wissenschaften und der Literatur in Mainz 5, 453-471.

Dodds, E. R., 1944, Euripides. Bacchae, Oxford.

Donzelli, G. B., 2006, "Il riso amaro di Dioniso. Euripides, Baccanti 170-369" en Medda,

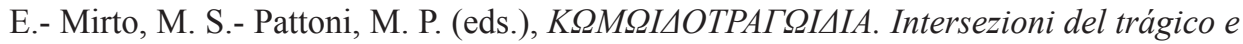
del comico nel teatro del V secolo a.C., Pisa, 1-17.

Edmonds III, R. G., 2013, Redefining Ancient Orphism, Cambridge.

Egli, F., 2003, Euripides im Kontext zeitgenössicher intellektueller Strömungen: Analyse der Funktion philosophischer Themen in den Tragödien und Fragmenten, München-Leipzig.

Encinas Reguero, M. C., 2011, "Los nombres de Dioniso en Las Bacantes de Eurípides y el lenguaje retórico de Tiresias", Humanitas 63, 123-142.

Ferrari, F., 2013, "From Orpheus to Teiresias: Solar issues in the Derveni Papyrus", ZPE 186, 70-72.

Gallistl, B., 1979, Teiresias in den Bakchen des Euripides, Würzburg.

Garvie, A., 2016, "Paradoxes and Themes in Bacchae" en D. Stuttard (ed.), Looking at Bacchae, London-New York, 109-120.

Gentili, B., 1995, Pindaro. Le Pitiche. Milano

González Merino, J. I., 2003, Eurípides. Bacantes, Córdoba.

Henrichs, A., 1975, "Two doxographical notes: Democritus and Prodicus on religion", HSPh 79, 93-123.

Kovacs, D., 2002, Euripides. Bacchae, Iphigenia at Aulis, Rhesus. Vol. VI, Cambridge-London.

Kitto, H. D. F., 1939, Greek Tragedy: A literary Study, London.

Leinieks, V., 1996, The City of Dionysus, Stuttgart.

Lloyd, G. E. R., 1964, "Hot and cold, dry and wet in early Greek philosophy", JHS 84, 92106.

Macías Otero, S., 2020, Bacantes. Eurípides. Edición bilingüe anotada y comentario, Madrid.

Macías Otero, S., en prensa, "La risa en las Bacantes de Eurípides: algunas actitudes de Penteo y Dioniso" en Actas del XV Congreso Español de Estudios Clásicos, Madrid.

Mirto, M. S., 2010, "Il dio nato duo volte: l'etimologia nelle Baccanti tra fede religiosa e critica del mito", Philologus 154, 3-24.

Murray, G., 1921, Essays and Addresses, London.

Norwood, G., 1908, The Riddle of the Bacchae, Manchester.

Oranje, O., 1984, Euripides'Bacchae. The play and its audience, Leiden. 
Piano, V., 2016, Il Papiro de Derveni tra religione e filosofia, Firenze.

Rijksbaron, A., 1991, Grammatical Observations on Euripides'Bacchae, Amsterdam

Riu, X., 1999, Dionysism and Comedy, Lanham-New York-Oxford.

Rivier, A., 1975, Essai sur le tragique d'Euripide, Paris.

Roth, P., 1984, “Teiresias as Mantis and Intellectual in Euripides' Bacchae", TAPhA 114, 59-69.

Roux, J., 1970, Euripide. Les Bacchantes. I. Introduction, texte et traduction, Paris.

Roux, J., 1972, Euripide. Les Bacchantes. II. Comentaire, Paris.

Santamaría, M. A., 2012, "Tiresias in Euripides' Bacchae and the author of the Derveni Papyrus" en Actes du 26 Congrès International de papyrology, 677-684.

Seaford, R., 1996 (22001): Euripides. Bacchae, Warminster.

Segal, Ch., 1982: Dionysiac Poetics and Euripides'Bacchae, Princeton.

Seidensticker, B., 1978, “Comic elements in Euripides' Bacchae", AJPh 99, 303-320.

Seidensticker, B., 1982, Palinotos Harmonia. Studien zu komischen Elementen in der griechischen Tragödie, Göttingen.

Seidensticker, B., 2016, "The figure of Teiresias in Euripides' Bacchae” en Kyriakou, P. Rengakos, A. (eds.), Wisdom and folly in Euripides, Berlin-Boston, 275-283.

Susanetti, D., 2016, “The Bacchae: Manipulation and Destruction" en Kyriakou, P. - Rengakos, A. (eds.), Wisdom and folly in Euripides, Berlin-Boston, 285-298.

Tovar, A., 1960, Eurípides. Tragedias. Las Bacantes, Hécuba. Vol. II, Barcelona.

Ugolini, G., 1995, Untersuchungen zur Figur des Sehers Teiresias, Tübingen.

Verdenius, W., 1988, “Cadmus, Tiresias, Pentheus. Notes on Euripides' Bacchae 170-369”, Mnemosyne 41, 241-268.

Winnington-Ingram, R. P., 1948, Euripides and Dionysus. An interpretation of the Bacchae, Cambridge. 